ESPECIAL

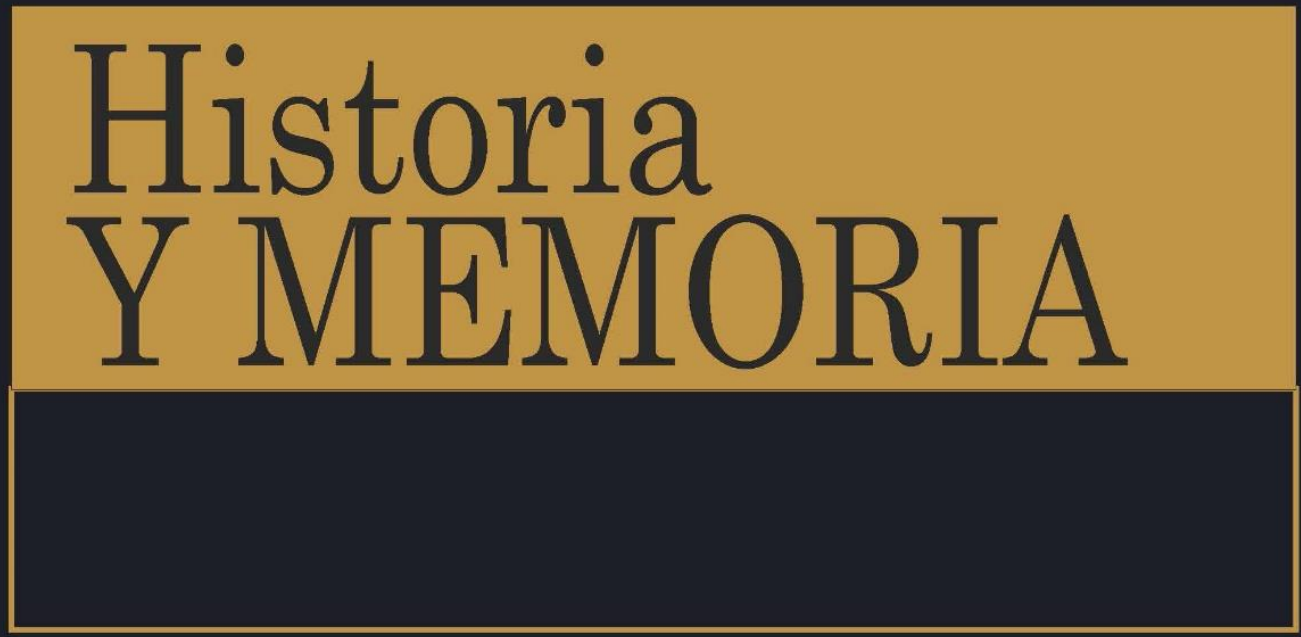

ISSN: 2027-5137 Número Especial • 10 Años • Año 2020 - Tunja, Colombia

El perpetuo conjuro: tiempo, colonialidad y repetición en la escritura de la historia

https://doi.org/10.19053/20275137.nespecial.2020.11590

Mario Rufer

Páginas 271-306

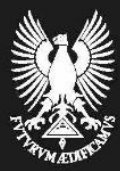




\title{
El perpetuo conjuro: tiempo, colonialidad y repetición en la escritura de la historia*
}

\author{
Mario Rufer ${ }^{1}$ \\ Universidad Autónoma Metropolitana, México
}

Recepción: 05/02/2020

Evaluación: 11/06/2020

Aprobación: 01/07/2020

Artículo de Investigación e Innovación

https:/doi.org/10.19053/20275137.nespecial.11590

"Cada discurso social borra los síntomas
que le han permitido nacer" ${ }^{2}$

\section{Resumen}

Este artículo analiza el vínculo de la escritura moderna de la historia con el dominio conquistador, con la soberanía impuesta por la guerra y con el ocultamiento de ese vínculo. Al mismo tiempo, postula que el desplazamiento de otras

\footnotetext{
* Este artículo se deriva del proyecto plurianual «Nación, temporalidad y poscolonialismo: conceptos para pensar América Latina», dirigido por Mario Rufer, (DCSH 014/09, Universidad Autónoma Metropolitana-Unidad Xochimilco, México). Agradezco los comentarios de Gustavo Verdesio, Laura Catelli y Alejandro de Oto a una primera versión resumida de este texto, que fue presentada como conferencia en el Coloquio «Las colonialidades instituidas», celebrado en el Centro de Investigaciones y Estudios de Teoría Poscolonial en la Universidad Nacional de Rosario, en agosto de 2019. Agradezco también las observaciones y sugerencias de los pares revisores anónimos de la revista Historia y Memoria.

1 Doctor en Estudios de Asia y África por El Colegio de México. Profesor-Investigador Titular en la Universidad Autónoma Metropolitana, México; Miembro del Sistema Nacional de Investigadores de CONACyT. Ha publicado: «La raza como efecto estructural de conquista. Una hipótesis de trabajo,» en Eva Alcántara, Yissel Arce y Rodrigo Parrini, eds., Lo complejo y lo transparente. Investigación transdisciplinaria en ciencias sociales (México: UAM-Imagia 2018), 101-128, junto con Olaf Kaltmeier, Entangled heritages. Postcolonial perspectives on the uses of the past in Latin America (Londres: Routledge, 2017), junto con Frida Gorbach, (In)disciplinar la investigación. Archivo, trabajo de campo y escritura (Siglo XXI Ed., 2017). $\bowtie$ mariorufer@gmail.com (1) https://orcid.org/0000-0002-2335-1335.

2 Michel De Certeau, La escritura de la historia (México: Universidad Iberoamericana, 2006), 285.
} 
formas de relación con el tiempo hacia la "cultura», constituye el doble epistémico de esa fórmula original de dominio. El texto se estructura en cuatro partes: 1 . Un estudio de la relación entre escritura y conquista; 2 . Un trabajo sobre el vínculo entre escritura de la historia y teoría de la soberanía, entre escritura de la historia y la colonialidad; 3. Un estudio de los procedimientos que relegaron en la cultura a las formas no lineales de relación con el tiempo, 4. Un abordaje de los mecanismos del historicismo que impiden pensar al anacronismo, la asincronía o la repetición como lógicas históricas subalternas.

Palabras clave: historia, soberanía, temporalidad, cultura, poscolonialismo.

\title{
The perpetual magic formula: time, colonialism and repetition in the writing of history
}

\begin{abstract}
This article analyzes the connection of the modern writing of history with the domination of the conqueror, the sovereignty imposed by war and the concealment of this connection. At the same time, this paper postulates that the shift of other forms of relation with time towards «culture» constitutes the double episteme of this original formula of domination. The test is structured in four parts: 1. A study of the relationship between writing and conquest; 2 . A work on the link between the writing of history and the theory of sovereignty, between the writing of history and colonialism; 3. A study of the procedures that relegated in culture the non-linear forms of relationship with time; 4 . An approach of the mechanisms of historicism which prevent the thought of anachronism, asynchrony or repetition as subordinate historical logics.
\end{abstract}

Key Words: history, sovereignty, temporality, culture, postcolonialism. 


\section{Le sortilège perpétuel : temps, colonialité et répétition dans l'écriture de l'histoire}

\section{Résumé}

Cet article analyse le lien de l'écriture moderne de l'histoire avec la domination du conquéreur, avec la souveraineté imposée par la guerre et avec l'occultation du lien en question. De plus, on tente de montrer que le déplacement d'autre formes de relation entre le temps et la "culture» constitue le double épistémique de cette formule originelle de domination. Pour ce faire, ce texte s'organise selon 4 parties: 1 . Une étude $\mathrm{du}$ rapport entre écriture et conquête; 2 . Un travail sur le lien entre écriture de l'histoire et théorie de la souveraineté, entre écriture de l'histoire et colonialité; 3. Une étude des procédures qui ont relégué de la culture toute forme non linéaire de rapport au temps; 4. Une analyse mécanismes de l'historicisme qui empêchent de penser l'anachronisme, l'asynchronie ou la répétition en tant que logiques historiques subalternes.

Mots-clés: histoire, souveraineté, temporalité, culture, postcolonialisme.

\section{Introducción}

Este texto parte de una conversación áulica que me llevó tiempo digerir. En una clase sobre memorias poscoloniales en la universidad donde trabajo en Ciudad de México, un estudiante de posgrado me increpó más o menos de la siguiente forma:

Usted dice que vivimos en modernidades coloniales, que hay una continuidad allí, una repetición. Continuidad de la violencia de conquista, continuidad necropolítica. Sin embargo, tengo un problema para entender eso. Cuando veo los muertos actuales, cuando veo los cuerpos desperdigados, mutilados, siento impotencia, rabia, ganas de llorar. Son, de alguna manera, mis muertos. Pero cuando fui al Museo Nacional de Antropología y vi los cuerpos mexicas, huesos de los sacrificados, los vencidos "profanados y exhibidos" 
digamos $^{3}$-aún cuando todo el discurso curatorial insiste en que de allí venimos-, no se me movió un pelo. ¿Por qué? ¿Sólo porque media tanto tiempo? ¿Por qué soy incapaz de percibir la repetición? ${ }^{4}$

El problema entre arqueología, exhibición y negativa de restitución de restos humanos en México está en el centro de la pregunta, pero excede a este texto ${ }^{5}$; sin embargo, mi reactiva respuesta fue más o menos la siguiente:

[...] creo que hay dos operaciones que podrían responder tu inquietud. La primera es histórica. La historia como saber produce una escisión fundamental. Nos dice que eso está muerto no sólo porque lo está orgánicamente, sino porque pertenece a un tiempo diferente e irrepetible. Al "pasado histórico" del historicismo. Es presentado como diferencia desde una potencia poderosa, una escritura legislativa. Muerto en tanto otro. La segunda operación es exhibitoria. Se exhibe lo muerto como texto taxonomizado, fragmentado, inocuo. Cuerpo del saber -científico-y metonimia de algo bello en otro lugar. Y como diría Arendt, hay que desconfiar de los pueblos embellecidos por el poder ${ }^{6}$. Esa doble operación es redituable. Por un lado, la historia hace posible que ese muerto que ves exhibido sea para ti pura diferencia. Distancia. Por otro, la exhibición pedagógica hace posible que esa ajenidad sea, también, quirúrgicamente bella en tanto no puede hacer nada más que ocupar ese lugar: no puede contravenir ese signo. Si esa liga entre historia y cultura se entiende, se comprende también que todo lo relativo al

3 Se refería al cuestionado acto de seguir exhibiendo restos óseos de poblaciones originarias en México, aún cuando todas las recomendaciones de ICOFOM, señalan el cese de la exhibición de restos indígenas y en su caso, la restitución a los territorios originarios que lo peticionen.

4 Clase de Seminario, «Estudios culturales y crítica poscolonial», Doctorado en Humanidades, UAM-Xochimilco, 2019. No puedo reproducir con fidelidad las palabras del estudiante porque las elaboró a partir del recuerdo y de mis notas de clase. Las cursivas refuerzan mi intención enfática.

5 La relación entre arqueología, soberanía y necropolítica es fundamental y poco estudiada. Paulina Álvarez hace aproximaciones nodales al respecto Paulina Álvarez, "Tres niños para la memoria. Arqueología, exhibición y poder en los Niños del Llullaillaco, Salta, Argentina"» (Tesis de Maestría, Universidad Autónoma Metropolitana, 2019), 185-192.

6 Referido en George Didi Huberman, Pueblos expuestos, pueblos figurantes (Buenos Aires: Manantial, 2014), 220. 
cuerpo muerto es un asunto de soberanía y de Estado. Un asunto del perpetuo dominio: conjurar el poder del Otro ${ }^{7}$.

Esta situación de clase me incomodó, sobre todo porque la respuesta que di fue puramente intuitiva. ¿Cómo opera el tiempo en el reconocimiento, en la diferenciación, en la conformación del pasado como ajeno y a la vez único, singular, irrepetible? ¿Qué relación guarda esa operación con la guerra, con el dominio, con la conquista? ¿Cómo es que la escritura de la historia produce un dominio propio y un "otro lugar» para lo que queda fuera de ese dominus? Esos interrogantes fueron los disparadores para escribir este texto.

Como estructura argumental, no me interesa tanto defender que existían -y existen- otras formas de narrar el pasado diferentes a una historia moderna que busca conexiones operativamente regladas entre acontecimiento pasado, evidencia presente y verdad. Eso es ya obvio. Me importa en todo caso analizar de qué modo la escritura moderna de la historia supone un vínculo indeleble con el dominio conquistador, con la soberanía impuesta por la guerra y con el ocultamiento de ese vínculo. Al mismo tiempo, relegar en el ámbito de la "cultura» a las otras formas de relación con el tiempo constituye el doble epistémico de esa fórmula primaria y original de conquista. En suma, me interesa mostrar que la escisión entre historia y cultura es previa a la definición disciplinar de la Historia y la Antropología, que está vinculada con la extensión de soberanía colonial y que es una fórmula que habilita modalidades de dominio moderno, garantizando su continuidad hasta hoy.

Lo que sigue se estructura en cuatro partes: primero, un análisis de la relación entre escritura de la historia y conquista del Nuevo Mundo, de los mecanismos de escritura como mímesis con formas de dominio y neutralización desde el poder imperial. En el segundo acápite, se analiza el vínculo inextricable entre soberanía, conquista y discurso de la historia. El tercer apartado, explora la escisión entre historia

7 Clase de Seminario, «Estudios culturales y crítica poscolonial», Doctorado en Humanidades, UAM-Xochimilco, 2019. 
y cultura: plantea cómo la potencia soberana desplazó a la cultura como aquello doblegado a la soberanía y sin atributos de temporalidad histórica, fórmula específica de extensión colonial y postcolonial del dominio. La última parte resume de qué forma el tiempo lineal, secuencial y vacío del historicismo (mediante las figuras de la especificidad, el anacronismo y el archivo) impidió que sea expresada con legitimidad una historia de la repetición de la conquista, del despojo o de la violencia.

\section{La escritura conquistadora}

En la apertura del prólogo de la segunda edición de $L a$ escritura de la historia, Michel de Certeau (2006) evoca la alegoría pictórica de Jan Van der Straet (1619) nombrada «El explorador (A. Vespuci) ante la india llamada América». En ella Amerigo Vespuci, «el descubridor», está de pie, con coraza, y «lleva las armas del sentido»; mientras América, «mujer acostada", es "presencia innominada de la diferencia ... Escena inaugural». Acto seguido el historiador francés anota: «el conquistador va a escribir el cuerpo de la otra y trazar en él su propia historia. Va a hacer de ella el cuerpo historiado el blasón- de sus trabajos y de sus fantasmas». Y sentenciará: "...lo que se esboza de esta manera es una colonización del cuerpo por el discurso del poder, la escritura conquistadora que va a utilizar al Nuevo Mundo como una página en blanco (salvaje) donde escribirá el querer occidental»».

De Certeau, pensador de la sospecha, rastreador de las fugas y omisiones del texto histórico, establece así al inicio de su Escritura, el vínculo indeleble entre escribir la historia y conquistar un mundo: entre grafía y dominio, entre producción de un texto y soberanía sobre un territorio. Pero aclaremos: primero, no es cualquier territorio sino la alegoría sobre un cuerpo de mujer. Segundo, no es cualquier tierra simbolizada cuerpo femenino: es América. El cuerpo historiado inaugural será "América latina»" ${ }^{9}$ Esta aclaración funciona como una

8 De Certeau, La escritura de la historia, 11.

9 De Certeau, La escritura de la historia, 11. 
advertencia, como una glosa en la obra. Es el único momento en el que el vínculo entre escritura, soberanía y cuerpo de mujer es tratado; y será el único espacio del libro -el que lo abre- en el que queda explícito el vínculo originario entre la escritura (moderna) de la historia y la Conquista de América ${ }^{10}$.

Hay conexiones más exploradas. La relación entre escritura y dominio del sentido es conocida, por ejemplo, en tanto registro y fijación de la oralidad. Dentro del orden colonial, son cruciales los aportes de Rolena Adorno ${ }^{11}$ y más tarde Walter Mignolo ${ }^{12}$ que trazaron rutas para reemplazar la expresión de «literaturas» coloniales por las de «discurso colonial» y "semiosis colonial» respectivamente. Esta discusión adquiere relevancia para nosotros en tanto alertaba tempranamente sobre un problema: cualquier noción que equiparara la discursividad social en situaciones de dominio colonial (como la americana) con conceptos ligados a la grafía, al corpus literario, corría el riesgo de soslayar los múltiples sistemas sígnicos que fueron obliterados, tachados o infravalorados por el dominio de la escritura. Pero esos puntos están bastante trabajados desde las lecturas multidisciplinarias de códices, quipus, crónicas de conquista y crónicas mestizas ${ }^{13}$. Lo que me parece menos explorado es la relación ex profeso borrada entre historia y conquista: entre

10 En los diferentes capítulos aparecerá el vínculo entre escritura y viaje, entre exploración de América y dominio, sobre todo en su conocido análisis de la obra del misionero Léry en Brasil. Pero la conexión entre la escritura de la historia como práctica textual y la Conquista de América como práctica de soberanía aparece explícita solo en el prólogo.

11 Rolena Adorno, «Reconsidering colonial discourse for Sixteenth and SeventeenthCentury Spanish America,» Latin American Research Review, n 3 (1993): 135-145.

12 Walter Mignolo, "Colonial and postcolonial discourse: cultural critique or academic colonialism?,» Latin American Research Review 28, n 3 (1993): 120-134; Walter Mignolo, «Semiosis colonial: la dialéctica entre representaciones fracturadas y hermenéuticas pluritópicas,» en De la hermenéutica y la semiosis colonial al pensar descolonial (Quito: Ediciones Abya Yala, 2013), 131-148; Walter Mignolo, El lado más oscuro del Renacimiento. Alfabetización, territorialidad y colonización, trad. Cristóbal Gnecco (Popayán: Universidad del Causa, 2016)

13 Elizabeth Hill Boone y Walter Mignolo, eds., Writing Without Words: Alternative Literacies in Mesoamerica and the Andes (Durham: Duke University Press, 1994), DOI: https://doi.org/10.1215/9780822379263. Mignolo, El lado más oscuro del Renacimiento. 
el mecanismo de la escritura de la historia y una fórmula específica de dominio sobre un territorio y sus sujetos.

Para un pensador como De Certeau, la forma escritural de la historia es no solo una técnica ni una forma de registro del pasado, sino básicamente una "continuidad de Occidente como conciencia ${ }^{14}$. En la operación historiográfica, la escritura tiene una función de reconocimiento de lo ajeno: su diferencia con la oralidad $-\mathrm{y}$ sus múltiples manifestaciones performativas- estriba en anclar el sentido mediante una extensión: "el lenguaje oral espera, para hablar, que una escritura lo recorra y sepa lo que dice ${ }^{15}$.

Lo recorra y sepa: la extensión al saber es una extensión de dominio a través del reconocimiento. Este último concepto es clave para los que trabajaremos más adelante: si exceptuamos las teorías de la subjetivación, la idea de reconocimiento tiene dos acepciones (que en realidad son la misma): la militar y la semiótica. Se reconoce un territorio cuando se avanza sobre él, cuando se lo domestica con los mojones, con el requerimiento o con la pirca. Se lo trae al mundo propio. Y se reconoce un signo cuando se lo trae al sentido, a la significación. La conciencia histórica de Occidente nacería entonces no tanto de un afán por registrar «lo que pasó» con veracidad y objetividad. La historia es homogénea, dirá de Certeau, porque "se desarrolla en la continuidad de las marcas dejadas por los procesos escriturísticos» ${ }^{16}$, en esa labor de reconocimiento, avance, fijación y muerte (reconocer y escribir en la superficie del texto y del tiempo lineal para dejar atrás, por siempre atrás).

Esta reflexión instala tres premisas para nuestras preguntas: primera, la escritura es menos una forma de «aproximación a la fijación y a la objetividad» que una actividad de extensión del dominio (esto es, de soberanía) sobre un cuerpo de saberes. Segunda, la escritura moderna de la historia estaría ligada tanto a un ejercicio de compilación,

14 De Certeau, La escritura de la historia, 204.

15 De Certeau, La escritura de la historia, 204.

16 De Certeau, La escritura de la historia, 204. 
de desciframiento o de análisis de un campo llamado «pasado», como a una operación generalmente no reconocida de domesticación: volver familiar lo extraño a partir de la producción de un saber sobre aquello que se desconoce. Ese saber es una forma de apropiación, de avance sobre el territorio de la alteridad. Tercera, si esa escritura oculta su principio epistemológico (recorrer y dominar mediante la producción de saber sobre aquello que no conoce), lo hace porque organiza su forma discursiva sobre una operación de sustitución: "al no poder convertir en objeto de estudio lo que es su postulado (el tiempo), la historia sustituye el conocimiento del tiempo por el conocimiento de lo que está en el tiempo» ${ }^{17}$. Promulgar que se trabaja "con el pasado" dejando de lado una reflexión sobre las formas de organización del tiempo (el vector pasado, presente y futuro), es una poderosa sustitución que asume como punto cero trascendente y universal a una manifestación contingente y parroquial: la forma que adquiere el tiempo vacío y homogéneo (moderno) del capital y del Estado en Occidente.

\section{Historia y soberanía}

En el comentario a la revisión crítica nigeriana de Dahomey and its Neighbors (1708-1818), el profesor I. Akinjogbin,

17 De Certeau, La escritura de la historia, 26; La advertencia de que los historiadores no «piensan» el tiempo sino que «operan» con él, está presente en pensadores tempranos como Carr. También lo plantea Hartog con claridad en Regímenes de historicidad (México: Universidad Iberoamericana, 2003), passim. En algún momento trabajé esta idea de que la temporalidad moderna es vista por el discurso histórico como un dato, no como un lenguaje. Al perderse su carácter de lenguaje, de gramática sobre la cual se significa el acontecimiento o el proceso, se pierde la posibilidad de pensar la política de la temporalidad: su direccionamiento de sentido, su imposición como tropología, su universalización como fondo de la experiencia individual y colectiva. Más allá de que el historicismo decimonónico es clave en esta generalización, es evidente que los siglos anteriores conforman la base para la escisión entre temporalidad (lineal) y "cultura», cuya intervención heterogénea sobre el tiempo impugna su carácter histórico. Para la reflexión más general véase Mario Rufer, «La temporalidad como política. Nación, formas de pasado y perspectivas poscoloniales,» Memoria y Sociedad, 14, 28 (2010): 11-31. Para un trabajo específico sobre temporalidades heterogéneas véase, entre otros, Mamadou Diuf, comp., L'historiographie indienne en débat. Colonialisme, nationalisme et sociétés postcoloniales (Paris: Sephis/Karthala, 1999); Partha Chatterjee, La nación en tiempo heterogéneo y otros estudios subalternos (Buenos Aires: Siglo XXI, 2004); Joanne Rappaport, The Politics of memory. Native historical interpretations in the Caribbean Andes (Londres: Cambridge University Press, 1990) 
prominente historiador beninés que estudió en profundidad el legado de los yoruba y de los fon en la conformación del Benín actual, explicaba lo siguiente:

La caída de Allada a manos de Dahomey en 1724 [reino de gran poder bajo dominio fon] significó una conquista única en la historia de larga duración de África Occidental. Pero debería yo aclarar que tuvo poco que ver con la caída del último emperador a manos de Francia 170 años después [1894]. Para ese entonces se habian introducido dos ideas fundamentales: la de historia y la de soberanía. No sé si los africanos hemos entendido el parentesco entre estos dos vocablos que nos llegaron de Europa y que hoy tomamos como nuestros ${ }^{18}$.

La advertencia de Akinjogbin es clara pero pocas veces trabajada por los historiadores: la connivencia entre historia y soberanía en la construcción de la diferencia entre Occidente y el Resto. En su trabajo renombrado, su tesis doctoral, Akinjogbin proponía que, si bien son innegables la guerra, la esclavización y la anexión de poblaciones en el continente africano desde mucho antes de la intrusión europea, existe, por lo general, en los relatos históricos africanos previos al colonialismo formal, una readaptación de las figuras históricas precedentes: por un lado, la posibilidad de que la narrativa sobre cómo fue el proceso de anexión o de guerra en el tiempo, sea disputada por los vencidos, impugnada, tachada ${ }^{19}$. En esa impugnación intervenían las muchas veces que el reino había sido invadido por los mismos invasores, como una mónada, como un "siempre-ya-sigue pasando", junto con el relato de imágenes superpuestas en el tiempo. El anacronismo era fundamental para mostrar el exceso de fuerza. La "verdad», si es que podemos usar esa noción, era un problema de poder y de posición (no de objetividad, de secuencia lógica ni de experimentación). A su vez, ese problema retórico afectaba la legitimidad de la ocupación y del gobierno del vencedor. En esta revisión de su obra seminal que hace Akinjogbin en 1982,

18 I. A. Akinjogbin, "Dahomey and its neighbors: a revisited history," West African History after Decolonization (Ifé: University of Ifé, 1982), 3.

19 Akinjogbin, I. A., Dahomey and its neighbors (1708-1818) (Cambridge: Cambridge University Press, 1967), 16-33. 
parecía decir: cuando Francia ocupó Dahomey, introdujo una teoría de la soberanía que ya contenía la idea de no-civilización y el derecho a civilizar, junto con una escritura de la historia (que ordenó dogmáticamente el tiempo, impidió la querella de posiciones e inscribió la singularidad indisputable del acontecimiento $)^{20}$. ¿Cómo se articula, filosófica y retóricamente, esa mancuerna entre conquista, soberanía y escritura de la historia?

Desde los trabajos de historiadores críticos del poder como Anthony Anghie que tematizaron el nacimiento del derecho internacional, sabemos que la noción positiva de derecho entre naciones derivada del iure gentium, no solo legitimó o coadyuvó a los procesos imperiales y de conquista, sino que fue consustancial a él. Para ser concreto: el derecho internacional necesitó de una teoría de la soberanía ligada a la conquista. La teoría de la soberanía en Occidente no precede a la conquista, sino que nace con ella. Y específicamente, de la conquista de América ${ }^{21}$; sin embargo, al propio Anghie lo movilizan las acciones de sustitución y silenciamiento de esa connivencia originaria. ¿Qué operaciones retóricas lo permitieron?

Michel Foucault ya había respondido a esa pregunta sin vacilar: fueron las operaciones de la historia. En Defender la sociedad ${ }^{22}$, sobre todo en las conferencias del 28 de enero y 4 de febrero de 1976, el autor se centra en la interdependencia

20 Véase Akinjogbin, I.A., Dahomey and its neighbors (1708-1818) (Cambridge: Cambridge University Press, 1967), 17-48. Un análisis de los procedimientos escriturales como la historia-disciplina se impuso en África Occidental y cuáles fueron sus mecanismos de elipsis, hipérbole y mímesis puede verse en Mario Rufer, Reinscripciones del pasado. Nación, destino y poscolonialismo en la historiografía de África Occidental (México: El Colegio de México, 2006), 4-27.

21 El trabajo de Anghie al respecto es extenso y articulado en varios textos. Anthony Anghie, «Francisco de Vitoria and the colonial origins of International Law.», en Laws of the postcolonial, ed. Eve Darian-Smith y Peter Fitzpatrick (Ann. Arbor: University of Michigan Press, 1999), 89-108. Anghie, Anthony, Imperialism, Sovereignty and the Making of International Law. (Cambridge: Cambridge University Press, 2004), DOI: https://doi.org/10.1017/CBO9780511614262.

(1999, 2004). La contraposición que hace Anghie deriva de un estudio pormenorizado del derecho canónico, el derecho natural y el derecho positivo (propio del viraje entre los siglos XVIII y XIX en Europa).

22 Michel Foucault, Defender la sociedad (México: FCE, 2002), 67-109. 
de las nociones de soberanía, conquista, raza e historia. $\mathrm{Su}$ argumento base es bastante conocido: después de las guerras de religión, y, sobre todo, con la revolución inglesa de mediados del siglo XVII surge en Europa central un discurso radicalmente nuevo que el autor denomina históricopolítico, en contraposición al discurso filosófico-jurídico. Este nuevo discurso articuló básicamente lo siguiente: a) que el discurso filosófico-jurídico que une al soberano con el pueblo y a la ley con la ciudad y con el Estado no es un discurso de identificación natural, sino un discurso de fortalecimiento de la soberanía que borra el sustrato coercitivo y violento que lo instaura y lo sostiene; b) que es necesario revertir la función de memorialización del pasado (ya no el recuerdo de la grandeza del poder real sino el recuerdo constante de que hay vencedores y vencidos, y de que la historia de unos existe en tanto se enfrenta (y niega) la historia de los otros; c) que lo que el discurso filosófico de la soberanía oculta es que el derecho se instaura a partir de la conquista (no de la voluntad), que la ley es coercitiva (no expresiva), y que lo que subyace en el terreno de lo político, por debajo y entre las expresiones rituales del poder soberano, es la guerra. La guerra constante. Pero no la guerra de "todos contra todos» à la Hobbes, sino una guerra binaria, una guerra de razas: la de los vencedores y la de los vencidos.

¿Por qué interesa esta inflexión aquí? En primer lugar, porque liga la aparición de un discurso histórico binario al acontecimiento de conquista: de expoliación, despojo y victoria sobre un territorio y sobre sus sujetos. En segundo lugar, porque Foucault une el problema de esta constitución de una "guerra de razas" basada en la conquista, al hecho colonial. Habremos de recordar que lo que él marcaba es el ocultamiento del hecho arbitrario, violento y accidental de la conquista como principio del orden que sustenta el a posteriori de ese acontecimiento: la ley, la voluntad y el contrato. La ley es expresión de un sujeto, y ese sujeto es el conquistador ${ }^{23}$.

23 Es claro que para Foucault lo interesante era disponibilizar una genealogía del racismo a partir de esta relación conquista/historia (y no una discusión con el canon disciplinar). Analizo la ligazón entre conquista y racismo en Rufer, «La raza como efecto estructural de conquista,» 101-128. 
En tercer lugar, y quizás lo más relevante a nuestro objeto, es que Foucault señala que la fuerza sustantiva para que la ley sostenga su expresión es mantener en secrecía ese origen. Secrecía posibilitada únicamente por un relato: la historia. Para él, la escritura de la historia muta en ese momento (siglo XVII precisamente) y adquiere como función primordial la constitución de un archivo como principio (de ley, de Estado) que pudiera, diríamos, "mantener el secreto" de que toda historia es una escritura de la soberanía y se apoya en un acto de subyugación ${ }^{24}$.

En consonancia con las ideas foucaultianas me interesa la precisión que instaura Anghie cuando, para trabajar los procedimientos retóricos que despojaron de soberanía a los indígenas americanos, Anghie analiza la obra del jurista y teólogo de la América conquistada, Francisco de Vitoria; específicamente su conocido De Jure Bellis Hispanorum in Barbaros, de 1532. Recordemos el célebre pasaje citado con frecuencia:

[...] si después que los españoles hubiesen mostrado con toda diligencia, por palabras y obras, que ellos no constituyen obstáculo para que los bárbaros vivan pacíficamente, éstos perseveraran en su malicia y maquinasen la perdición de los españoles, éstos podrían obrar no ya como si se tratara de

\footnotetext{
24 Foucault quiere mostrar lo que la teoría filosófico-jurídica de la soberanía se empeñará en ocultar de ahí en adelante: ocultar que no existe el sujeto neutral del derecho (lo que después será el Sujeto Universal kantiano), sino que existen dos historias y dos sujetos posicionados, la historia de los vencedores y la historia de los vencidos y sus correspondientes sujetos. Ocultar que la historia de los vencidos fue apenas codificada y más tarde sustraída de su posición de enunciación por parte de las voluntades del Estado. Ocultar que la noción de soberanía no está amparada en la voluntad, en la cesión ni en el contrato, sino en el acontecimiento fundante de la conquista y en la guerra permanente para sostenerla. Y ocultar que el derecho es una trampa que expresa lo que esa conquista necesita hacer prevalecer bajo la forma inocua de la voluntad y del bien común. El interlocutor central de Foucault es Hobbes y su lectura es implacable. «En una palabra, lo que Hobbes quiere eliminar es la conquista e incluso la utilización, en el discurso histórico y en la práctica política, del problema de la conquista». Foucault, Defender la sociedad, 94. Es pertinente recordar que a Foucault le interesaba este análisis con respecto a prácticas específicas (yo no al «discurso de la raza» o al «discurso del Estado»). En esas prácticas, los discursos se «desenmarcan» de los contextos y se encarnan en posiciones de sujeto y autoridad, circulando en relaciones de poder específicas. Esa será la característica clave tantas veces citada como "saber/poder» que potencia la eficacia de las formaciones discursivas.
} 
inocentes, sino de adversarios pérfidos, haciéndoles sentir todo el rigor de los derechos de la guerra despojándolos de sus bienes, reduciéndolos a cautiverio y destituyendo a los antiguos señores y estableciendo a otros en su lugar; pero todo esto con moderación y en proporción a los hechos y a las injurias recibidas [...] Por lo demás, es principio general del derecho de gentes que todas las cosas tomadas de la guerra pasen a poder del vencedor ${ }^{25}$.

Este texto es una muestra de la atención que puso Vitoria a los rituales, las costumbres y los «modos de vida» indígenas como un argumento con fuerza de ley. Nos interesa por lo siguiente: la aparente contradicción de Vitoria en otorgar dignidad y razonamiento a los indígenas, pero negarles la soberanía, radicaría en que los indígenas americanos tenían razón y alma y a pesar de ello, permanecían en el error, «perseveran en su malicia». ¿Por qué? Porque algo como «su cultura», en la forma de carencia, aparece como un escollo insalvable y porque salvarla es una cuestión de soberanía. Si el soberano (Rey/Dios) no se elige, se adquiere a través de la conquista.

Anthony Anghie pone el acento en ese punto clave: la teoría de la soberanía de Francisco de Vitoria, para muchos la "primera» en el mundo, es el resultado de su «intento de lidiar con la diferencia cultural $»^{26}$. El anacronismo con el concepto (diferencia cultural) no me parece una licencia sino una importante conexión. Vitoria sería el pionero en el siglo XVI al desplazar el problema de un "orden entre distintos estados» (aparentemente consustancial al derecho internacional incipiente) hacia un orden «entre sociedades constituidas por sistemas culturales diferentes» ${ }^{27}$. Para Vitoria, «el indio -que aún poseyendo razón universal sigue sin embargo atrasado, bárbaro e incivilizado- es sujeto a la sanción de la ley a causa

25 Francisco de Vitoria, Relecciones sobre los indios y el derecho de guerra (Madrid: Espasa Calpe, 1975), 95.

26 Anthony Anghie, «Francisco de Vitoria and the colonial origins of International Law,» en Laws of the postcolonial, ed. Eve Darian-Smith y Peter Fitzpatrick (Ann Arbor: The University of Michigan Press, 1999), 90.

27 Anthony Anghie, Imperialism, Sovereignty and the Making of International Law (Cambridge: Cambridge University Press, 2004), 46. 
de su fracaso para cumplir con los estándares universales requeridos ${ }^{28}$.

Sabemos que fue la teoría del derecho positivo la que forjó una relación directa con el colonialismo y fundamentalmente el derecho internacional que, aquí sí, distinguió entre estados civilizados y estados que no lo eran, y sostuvo que la soberanía aplicaba sólo para «la familia de naciones civilizadas»" ${ }^{29}$ Para Anghie esto tiene una característica central: «el orden [internacional] no se creó entre estados soberanos, sino entre entidades caracterizadas como pertenecientes a sistemas culturales enteramente diferentes $»^{30}$. El asunto clave que el autor no dice es que ese procedimiento retórico de "crear» una noción de pueblos con sistemas de normas diferentes (y algunos, «atrasados», por ende, no-civilizados), fue posible porque un procedimiento técnico de escritura lo habilitó: el que desplazó la otredad como cultura estable y escribió la identidad conquistadora como relato temporal, vectorial y potente de soberanía. Discurso histórico.

La pregunta que salta aquí es: ¿por qué hablar del vínculo entre historia y conquista y específicamente entre historia y conquista de América cuando es evidente que en el momento de la intrusión, ya existían en Europa formas claras de «hacer historia» legadas del Renacimiento? La obra monumental de Walter Mignolo, El lado más oscuro del Renacimiento, es quizás el intento más claro de respuesta. El texto empieza con una clara aseveración: "este libro trata sobre la colonización de lenguas, de memoria y del espacio que tuvo lugar cuando la "cuarta parte" del mundo, el Nuevo Mundo, emergió a la conciencia europea» ${ }^{31}$. Más allá del análisis de un corpus específico de códices, crónicas mestizas y obras misioneras, el libro de Mignolo reconoce como base la noción de que la colonización de espacio y de memoria son fundamentales para comprender el proceso de significación de la construcción

28 Anghie, Imperialism, Sovereignty and the Making of International Law,46

29 Anghie, Imperialism, Sovereignty and the Making of International Law, 35.

30 Anghie, Imperialism, Sovereignty and the Making of International Law, 36.

31 Mignolo, El lado más oscuro del Renacimiento. 37. 
imperial más general. El autor lo explica con una intuición fundamental: cuando los castellanos hablaron de la «falta de historia» de los mexica o los mayas, no se referían por supuesto a la falta de acontecimientos importantes sino a la falta de narraciones sobre ellos. A las inscripciones picto-ideográficas las tomaron muy en serio, pero como fuentes, como tomaban «la evidencia aportada por las monedas o las medallas» en Europa $^{32}$. O sea, como documentos. Como cultura. La tesis de Anghie relativa al dominio y la ley negados, aparece aquí espejada en su doble, la condición histórica vedada.

Por tenue que sea, esta operación es fundamental: los conquistadores castellanos subsumen las organizaciones epistemológicas originarias sobre el tiempo y su narración desconociéndoles el carácter de historias. Proponiéndolas como evidencias para una historia propia, castellana, que se encastraba en un tiempo ya secuencial pero aún no vacío, porque era el tiempo cristiano: y una historia que no tenía Dios solo era el documento que probaba su falta y el mismo que habilitaba su necesidad. Es aquí donde adquiere densidad empírica el dictum de De Certeau sobre el desarrollo de la escritura de la historia como conciencia de Occidente. Esa subsunción (una producción vernácula de historia negada, transformada por la Conquista en una evidencia sobre la falta de historia) es clave como acto de soberanía. Es una conciencia que en el mismo acto de enunciarse «borra los síntomas» que le permitieron nacer. Así, al posicionar a la Conquista en el relato como acontecimiento, se impide percibir la connivencia estructural que ella guarda como fundamento del relato.

\section{La cultura como pacificación}

«¿Qué es eso que está fuera del texto y que sin embargo, se nota en él? ${ }^{33}$.

Las formas locales de registrar el pasado no solo fueron colonizadas, extirpadas o infravaloradas: fueron, prolijamente,

32 Mignolo, El lado más oscuro del Renacimiento, 171.

33 De Certeau, La cultura en plural, 240. 
relegadas al lugar de documento de cultura. Quiero decir: la colonización del imaginario temporal ${ }^{34}$ no se produjo solamente sustituyendo una mecánica por otra, una gramática cíclica o elíptica del tiempo pre-intrusión sobre una homogénea, teleológica y cristiana. La operación fue más sutil y se produjo habilitando un lenguaje formal: aquellas formas de imaginar los ciclos, la repetición o la elipsis, como lógicas históricas fueron relegadas a "cultura otra», un sistema diferenciado. Fue esta la operación epistémica más poderosa en términos de la instauración paulatina de la "colonialidad del poder» ${ }^{35}$.

Si esa labor comenzó con los conquistadores y frailes castellanos en aquella subsunción de un relato histórico por una evidencia de cultura ${ }^{36}$, si esa subsunción fue clave para apoyar una teoría de la soberanía que humanizara a los indígenas para al mismo tiempo ponerlos en el plano del error y de la diferencia, será la labor de los nacionalismos latinoamericanos la que refuerce aquella fórmula conquistadora y selle su carácter racista ${ }^{37}$. Es así que salta la

34 Serge Gruzinski trabaja con densidad empírica los procedimientos locales como esta colonización se implementa entre ambivalencias, apropiaciones y sincretismos. Serge Gruzinski, La colonización de lo imaginario. Sociedades indígenas y occidentalización en México, siglos XVI-XVIII (México: FCE, 1991).

35 Recordemos que, en definitiva, este mismo texto que escribo se trata de dar densidad empírica a la premisa tempranamente elaborada por el sociólogo peruano Aníbal Quijano, muchas veces usada a la ligera y sin justicia a su propia genealogía. Para Quijano era fundamental el trabajo sobre las oclusiones temporales: la persistencia de la colonia solo podía ser entendida como una estructuración mutante de poder que excedía al ámbito político del imperio o los virreinatos y a la periodización estricta del «período colonial». La colonialidad del poder sería entonces una estructura trans-temporal de dominación que oculta básicamente dos acontecimientos: el origen bélico de esa estructura y el sustrato racializante que impuso. Véase: Aníbal Quijano, "Colonialidad del poder, eurocentrismo y América Latina,» en Colonialidad del saber. Eurocentrismo y ciencias sociales. Perspectivas Latinoamericanas, comp. Edgardo Lander (Buenos Aires: CLACSO, 2000), 201-246. Para un análisis potente sobre la actualidad del pensamiento de Quijano, véase: Rita Segato, La colonialidad en ocho ensayos y una antropología por demanda (Buenos Aires: Prometeo, 2015).

36 Mignolo, El lado más oscuro del Renacimiento; Peter Hulme, Colonial Encounters: Europe and the Native Caribbean, 1492-1797 (Londres: Routledge, 1986).

37 José Klor de Alva, "Colonialism and Postcolonialism as (Latin) American Mirages," Colonial Latin American Review, I, 1-2 (1992): 3-23; Para México, investigaciones como las de Margarita Carbó, «De la República de Indios a la corporación civil. Vivir bajo permanente amenaza,» Scripta Nova. Revista Electrónica de Geografía y Ciencias Sociales Vol. X, no 218 (2008): 741-798; Alicia Castellanos, 
familiaridad de los mecanismos imperiales de Gran Bretaña o Francia con los de las élites criollas latinoamericanas, que crearon las repúblicas mediante la negación de historicidad a sus otros (coloniales o nacionales) ${ }^{38}$. Ese movimiento de repúblicas independientes haciendo mímesis con mecanismos coloniales no es contradictorio: significó el triunfo irrestricto del historicismo como filosofía de la historia mostrado por Chakrabarty ${ }^{39}$.

La historia secuencial, lineal y homogénea ha sido ya mundanizada por el secularismo (con el apoyo ambivalente del mito nacional), y por ende es vectorial y unidireccional hacia el progreso, la conformación política del estado moderno y la vehiculización del capitalismo.

No puedo abordar aquí la complejidad en el "uso» más reciente del concepto de cultura que asociamos desde finales del siglo XIX, con la genealogía de la disciplina antropológica (y con una patrística que va de Taylor a Boas). Pero un asunto es sintomático. Antropólogos prominentes

«Para hacer nación: discursos racistas en el México decimonónico,» en Los caminos del racismo en México, coord. José Jorge Gómez Izquierdo (México: Plaza y Valdes Ed., 2005), 89-115 y José Gómez Izquierdo, «Racismo y nacionalismo en el discurso de las élites mexicanas. Historia patria y antropología indigenista,» en Los caminos del racismo en México, coord. José Jorge Gómez Izquierdo (México: Plaza y Valdés Ed., 2005), 117-143. muestran de qué manera la idea de eliminación del indio, si no aparecía como figura o como posibilidad política, sí aparecía como deseo en algunos intelectuales que escribían las historias, junto con un desprecio declarado sobre ciertos sujetos «inevitables» pero desechables por "peligrosos y anacrónicos» (se evidencia en la larga duración en el caso de Carbó y en los proyectos de nación del siglo XIX en los casos de Castellanos y Gómez Izquierdo). La historia era escrita con ese deseo soberano de fondo. A su vez, estos autores hacen un análisis de la apropiación de la figura de "derecho de guerra» de De Vitoria en los historiadores conservadores mexicanos como Alamán (y reapropiado también en el siglo XX por figuras como Esquivel y Vasconcelos). Muestran cómo una idea nunca explícita de historia era el vehículo de la expresión soberana con ese fundamento conquistador (y negador de historicidad) detrás.

38 Mary Louise Pratt, «In the Neocolony: Destiny, Destination and the Traffic in Meaning,» en Coloniality at large. Latin America and the Postcolonial Debate, ed. Mabel Moraña, E. Dussel y C. Jáuregui (Durham: Duke University Press, 2008), 459477; Valeria Añón y Mario Rufer, «Lo colonial como silencio, la conquista como tabú: reflexiones en tiempo presente,» Tabula Rasa, n 29 (2018): 107-131, DOI: https://doi. org/10.25058/20112742.n29.06.

39 Dipesh Chakrabarty, Provincializing Europe. Postcolonial Thought and historical difference (Princeton: Princeton University Press, 2000), 27-45. 
como Annelise Riles ${ }^{40}$ analizan la obra de algunos juristas en el proceso de invención del derecho internacional (entre fines del siglo XVIII y principios del XIX) para demostrar que tanto la noción positiva de derecho (en contrapunto a la natural) como la aparición del evolucionismo y de la idea de cultura en el horizonte antropológico decimonónico, fueron fundamentales para la conversión de la teoría secular de la soberanía y la aparición del derecho internacional, o sea, para la aparición de una ley entre pueblos soberanos "civilizados» y simultáneamente una habilitación del dominio imperial para los que no lo eran. Johannes Fabián ${ }^{41}$ demostró con claridad la labor de la antropología en la negación de la coetaneidad al objeto antropológico (denial of coevalness) y la espacialización del tiempo del Otro. Sin embargo, pareciera existir un consenso en que la historia como discurso no reviste complicidad alguna en este proceso. La historia simplemente dice "registrar» el hecho de la aparición del estado nación moderno en un plano temporal que es secuencial y ahora sí, después de la Paz de Westfalia de 1648 por lo menos, vacío. Si el tiempo histórico moderno expulsó a Dios para dar cabida al Estado, me parece cada vez más claro que lo hizo conjurando la posibilidad de que su propia naturaleza fuera pensada como un acto de dominio: la propia naturaleza del tiempo moderno en tanto tiempo de la soberanía.

En ese proceso de escisión, las élites criollas cumplieron un rol fundamental. Trabajaron meticulosamente la división entre historia y cultura hacia finales del siglo XIX y principios del XX, elevando a la cultura originaria como tradición, reliquia inocua, texto digno de ser emblema, pero negándole estatuto de historia ${ }^{42}$. Más allá de que cada sintaxis nacional

40 Annelise Riles, «Aspiration and control: International legal rhetoric and the essentialization of culture,» Harvard Law Review, 106, 3 (1993): 723-740.

41 Johannes Fabián, Time and the Other. How Anthropology Makes its Object (Nueva York: Columbia University Press, 1983), 27-31.

42 La «complicidad» de las élites criollas en la ambivalencia por romper políticamente con la metrópoli, pero utilizar las estructuras de dominación locales fue más exitosamente evidenciada en las literaturas vernáculas que en la historiografía. Arguedas es un maestro de esta demostración en: José María Arguedas, Todas las sangres (Lima: Editorial Horizonte, 2015); Rosario Castellanos en México escribe otra gran obra -valorada mucho después- sobre el carácter trágico de lo colonial en el 
debe analizarse en su especificidad, es importante destacar el súbito salto por el cual los cuerpos conquistados de la colonia pasan a ser reliquias embellecidas de la nación ${ }^{43}$, heráldicas locales ${ }^{44}$, cultura "reconocida» y «rescatada». Este paso debe analizarse como el doble retórico de la escritura de la historia: la conquista se volvió pasado puro, irrepetible. Y los conquistados tornáronse cuerpos embellecidos por el poder soberano de las élites criollas que los transformó en cultura, «belleza del muerto» ", vitrinas inocuas a las que les fue despojada su potencia de dominio, su fuerza legítima de contradicción, y les fue denegada una narrativa de experiencia histórica, subsumida en el relato nacional y sustraída en la ley positiva de la república. Digamos que la cultura ha sido, en ese movimiento, pacificada.

Vivimos bajo esa dualidad: una historia (casi siempre nacional) y una proliferación de narrativas inertes sobre el pluralismo cultural. Para el discurso de la gubernamentalidad actual hay una paradoja clave: la nación podrá ser multicultural, pero no multihistórica. Muchas culturas mientras no pongan en peligro a una historia única, secuencial, irrepetible, amparada silenciosamente en el espacio de referencia nacional. La retórica contemporánea del reconocimiento es entonces una hospitalidad de estado que obvia decir que la historia -como narrativa que sedimenta un pueblo- sigue siendo concebida como única, más allá de las diatribas disciplinares de sus versiones ${ }^{46}$.

seno de la cultura mestiza nacional, Rosario Castellanos, Balún Canán (México: FCE, 2006). Desde los análisis historiográficos es ejemplar la compilación de Mark Thurner y Andrés Guerrero, eds., After Spanish rule. Postcolonial predicaments of the Americas (Durham: Duke University Press, 2003), DOI: https://doi.org/10.1215/9780822385332.

43 Mario Rufer, «La tradición como reliquia. Nación e identidad desde los estudios culturales,» en Nación y estudios culturales. Debates desde la poscolonialidad, ed. Carmen de la Peza y Mario Rufer (México: UAM-Itaca, 2016), 37-59.

44 Rita Segato, La nación y sus otros (Buenos Aires: Prometeo, 2007), 138-139.

45 Michel De Certeau, La cultura en plural (Buenos Aires: Nueva Visión, 2009), 47-70.

46 Tomemos el caso de la Constitución Política de los Estados Unidos Mexicanos, artículo 2, 2001, 8 de agosto, de las Garantías Individuales que comienza diciendo a la letra: "La Nación Mexicana es única e indivisible», para agregar a continuación que « la Nación tiene una composición pluricultural sustentada originalmente en sus pueblos indígenas que son aquellos que descienden de poblaciones que habitaban en el territorio actual del país al iniciarse la colonización...» (CPEUM, Art. 2). Si es 
Para entender la relación que refuerza la redituable escisión entre historia y cultura, quisiera moverme por un momento al discurso judicial, y no es novedad que el complemento entre las políticas de identificación y las formas de definición de lo aceptable y de lo punible dicen mucho sobre las modalidades permitidas de permanecer y de narrarse como pueblo. El Código Federal de Procedimientos Penales de México prescribe, en su Artículo 220 Bis, lo siguiente:

Cuando el inculpado pertenezca a un grupo étnico indígena, se procurará allegarse dictámenes periciales, a fin de que el juzgador ahonde en el conocimiento de su personalidad y capte su diferencia cultural respecto a la cultura media nacional[...] [énfasis mío] ${ }^{47}$.

La vigencia de esa voluntad soberana que reconoce y otorga en la medida que capta y gobierna, queda explícita en la producción no solo de la diferencia, sino de una "cultura media» nacional que es el ojo observador, el punto cero sobre el cual no es posible adquirir un parámetro mesurable, no necesita explicación. Esa «cultura media» no admite diferencia justamente porque está amparada en el sujeto histórico de la nación: ese sujeto escribiente, dominus escritural de la pluma y la espada, grafía conquistadora, es el que permanece intacto en contextos poscoloniales. La "cultura media» hace historia. La cultura otra, «reconocida», afirma la soberanía.

\section{El conjuro de la repetición}

«Quisiera subrayar la cuestión abierta por el retorno del Otro al discurso que lo prohíbe» ${ }^{48}$.

Vuelvo a la pregunta que se hacía mi estudiante, ¿por qué la visión de aquellos muertos "no me movió ni un pelo»? Para entenderla sería prudente que nos preguntáramos si la reflexión histórica, en su obsesión sobre las nociones de "proceso» y

única pero compuesta por una variedad de culturas, ¿en qué radica su unicidad? ¿En la historia, que no amerita dobles ni contravenciones?

47 Código Federal de Procedimientos Penales. 2016, 17 de junio. Capítulo IV, Peritos.

48 De Certeau, La escritura de la historia, 241 
«especificidad», no abandonó demasiado rápidamente y con serios riesgos una teoría crítica sobre la continuidad, sobre la repetición diferida y sobre la estructura heterogénea de la temporalidad (entendida no como "reconocer varias culturas del tiempo", sino como parte nodal de una epistemología de la historia $)^{49}$.

Sabemos que la escritura de la historia se forja en una relación específica con la alteridad y con la muerte. La relación con la ajenidad pasa de algún modo por la cooptación de un «fuera de texto» en la escritura ${ }^{50}$. Pero la relación de la historia con la muerte atraviesa un doble movimiento indisoluble: por

49 Rita Segato lo plantea así: «[tenemos] la necesidad de percibir una continuidad histórica entre la conquista, el ordenamiento colonial del mundo y la formación poscolonial republicana que se extiende hasta hoy». Rita Segato, «El color de la cárcel en América Latina. Apuntes sobre la colonialidad de la justicia en un continente en desconstrucción,» Nueva Sociedad, 208 (marzo-abril, 2007), 158. ¿Cómo defender la continuidad después de Foucault, quien criticó duramente a la historia por productora de continuidades y temerosa de la irrupción? Cierto. Pero lo que criticaba el filósofo francés era una historia de la continuidad que desconoce la repetición: criticaba la característica vectorial, cadena de singularidades con un sentido único que pondera cada acontecimiento como excepcional. La continuidad que no se ve y que pretendo defender aquí, es la repetición de la traición soberana. Esa repetición es refractaria al signo, renuente a la representación, porque el lenguaje estratégico de la ciencia histórica (el documento), se funda en una irrupción no reconocida (la nación, la política de estado, la construcción liberal de la ciudadanía). Véase Michel Foucault, La arqueología del saber (México: Siglo XXI, 2010), 14-21.

50 Cuando De Certeau trabaja sobre la forma del lenguaje alterado en la palabra de las posesas del siglo XVII francés, cobra fuerza una tesis específica: la escritura de la historia es una forma de cooptación de un fuera de texto. La escena de la posesión que puede ser periférica a la historia en tanto pasado- revela sin embargo algo que es central en la historia en tanto episteme. Al menos después de la expansión europea, la historia se constituye como saber al traer al discurso algo que no es discurso (en tanto no se conocen sus reglas de operación): y para traerlo necesita fragmentarlo, citarlo (en su doble acepción de convocar y referir), nombrar aquello que desconoce y situarlo en el único plano conocido (el tiempo cristiano). La posesa del siglo XVII, dice el historiador francés, solamente puede hablar como poseída. La suya es una situación solo compatible con la oralidad. En la medida en que pasa al discurso escrito, a la organización de un saber sobre la superficie escritural, ese "otro que habla en mí» se organiza no como el conocimiento verdadero de eso que habló, sino como una técnica de familiarización, de domesticación y dominio sobre lo hablado. Se introduce al otro en el texto de lo mismo. La historia hace mímesis entonces con otros discursos colindantes: «el discurso demonológico, el discurso etnográfico o el discurso médico toman respecto a la posesa, al salvaje o al enfermo, la misma posición: 'yo sé mejor que tú lo que tú dices' (...)» (:241, cursivas en original). La historia retoma tempranamente «la metáfora clínica de la extracción», dirá Frida Gorbach en "El historiador, el archivo y la producción de evidencia,» en (In)disciplinar la investigación. Archivo, trabajo de campo y escritura, eds. Frida Gorbach y Mario Rufer (México: siglo XX, 2017), 194. 
un lado, es el trabajo con los muertos; por otro, es aquello que la propia escritura declara muerto: escribir el pasado es una forma de producir una diferencia sobre aquello que necesita estar muerto; esto es, ser distancia ${ }^{51}$. Esta relación es consustancial a la consolidación de la idea vacía y lineal de tiempo, y al nacimiento de una forma de pasado (eurocentrada y moderna): la que lo postula como ausencia total y como irrepetible. Esa es la doble relación con la muerte que el "pasado histórico» inaugura. Koselleck ${ }^{52}$ y más recientemente Hartog ${ }^{53}$ especificaron las modulaciones con las que el historicismo echó por tierra la idea de historia magistra vitae: el pasado histórico adquirió no solamente la característica de ser verificable y comprobable "tal cual fue» à la Ranke, sino que ya no podrá ser. Una interdicción fundamental del historicismo es la no repetición del acontecimiento. Secuencial, homogéneo, procesual, progresivo e irrepetible.

Así, la relación con el pasado en tanto Otro muerto, diferencia irrepetible, es complementada por la relación con la alteridad en tanto diferencia conjurada, distancia traída al texto por los mecanismos de la cita, del archivo, de la evidencia y de la organización temporal secuencial ${ }^{54}$. Tanto la noción de singularidad irrepetible como la de diferencia conjurada son, sin duda alguna, poderosas ficciones de la escritura histórica ${ }^{55}$.

51 De Certeau, La escritura de la historia, 17.

52 Koselleck, Futuro pasado. Para una semántica de los tiempos históricos.

53 François Hartog, Régimes d'historicité. Présentisme et expériences du temps (Paris: Le Seuil, 2003).

54 Michael Taussig lo postuló así al hablar de la magia del Estado: la escritura (de la antropología y de "algunas ramas de la historiografía» tendría un rol de conjuro con la alteridad; el poder mágico de la diferencia se neutraliza porque su escritura se disponibiliza al Estado, se propone como arte de gobernar. El dominio en tanto coerción solo es posible desde el complemento que otorga ese conjuro, esa neutralización escritural. Michael Taussig, La magia del Estado (México: Siglo XXI, 2015), 223-224.

55 Incluso en los más vehementes críticos europeos del historicismo -la Escuela de Annales y la inscripción braudeliana de los tres tiempos- hay un tácito acuerdo en que el sustrato del tiempo histórico (su carácter vector) y del acontecimiento (su condición de singular) no están a discusión. Se discute en todo caso la escala de la temporalidad y su mayor o menor poder explicativo sobre los procesos. Pero la condición para "pensar históricamente» en clave disciplinar ya sea en el historicismo decimonónico, en la escuela de Annales francesa o en la Begriffsgeschichte alemana, es tomar al tiempo histórico como secular, irrepetible y diferido. 
Pero hablar de repetición exige cautela. Spivak ${ }^{56}$ alertaba tempranamente que una crítica al colonialismo y a sus marcas en el presente no puede sostenerse sobre la base de una continuidad serial, como si toda historia fuera la misma, justamente porque el colonialismo reedita y recompone los modos para nombrar la operación por la cual extiende sus formas de dominio: extiende soberanía en el reconocimiento de sus súbditos-ciudadanos, pero mantiene indemne modos de jerarquía, racialización, explotación y despojo. La continuidad del colonialismo radicaría, justamente, en su «capacidad para presentarse como otra cosa», para que la violencia repetida de una muerte por rapiña, avance y despojo, «no nos mueva ni un pelo». Esa capacidad es vehiculizada principalmente por el tiempo histórico de la soberanía y de la singularidad, y es ejecutada intermitentemente hacia sus otros internos por los estados nación republicanos.

¿Cómo es que "permanece conjurada» esa posibilidad de analizar la historia como repetición? Porque está claro que, si la disciplina opera sobre el tiempo homogéneo, lo hace sin caprichos: con archivo, evidencia y lógica de la prueba. ¿No es, entonces, demostrable la repetición?

Si acordamos con Derrida, quien pensó más filosófica y políticamente el tema del archivo, debemos recordar que este tendría tres funciones que son fundacionales para el discurso de la historia: las de ser un arconte, una autoridad y una forma de consignación ${ }^{57}$. Arconte como lugar que ampara y resguarda, con lo ritual que la acción implica, autoridad porque compone la evidencia (la dimensión de ley que consagra al archivo) y la facultad de consignación como poder para sistematizar, organizar, conjuntar. En gran parte, la labor de administración de poblaciones que el Estado moderno debe garantizar depende del archivo y es vehiculizada por él.

56 Gayatri Spivak, Crítica de la razón poscolonial (Madrid: Akal, 2009), 107.

57 Jacques Derrida, Mal de archivo. Una impresión freudiana (Madrid: Trotta, 1997). 
Cuando el poder colonial de facto es sustituido por uno republicano que llamaremos aquí "de conquista diferida", se produce una operación fundacional con la temporalidad y con el archivo: el tiempo secuencial, lineal y episódico garantiza el arrojo de la soberanía por conquista al pasado histórico irrepetible; y el archivo desempeña dos roles centrales: en uno, mediante el poder de consignación formaliza un trabajo metonímico por el cual la organización de las partes se torna el sistema completo de enunciabilidad de la historia ${ }^{58}$. En el otro, el ejercicio de la autoridad avala que el sistema de enunciados de verdad se dispute fuera del ámbito político de la significación y del discurso, un terreno siempre resbaladizo. En cambio, a ese sistema se lo propone como un dictum verdadero sobre aquello que por definición es ausencia (el pasado). Pensemos que la diplomática, en tanto crítica formal externa e interna de los documentos como "prueba de verdad», avala ese acto: homologa la autenticidad de un soporte simbólico (un documento) con la única prueba de paseidad. Como resultado, lo que «no aparece en la superficie» del archivo, no puede ser considerado pasado histórico con pretensiones de verdad ${ }^{59}$.

Cuando entramos en el terreno de la «diferencia cultural», de las bellezas pacificadas que no son reconocidas como historia (por no secuenciales ni contar con archivo), vemos que

58 Rufer, «El archivo. De la metáfora extractiva a la ruptura poscolonial,» 160-186.

59 Aquí se introduce un tópico que no podemos abordar in extenso: la naturaleza más intuitiva que científica del conocimiento histórico, tal como lo proclamara Carlo Ginzburg en su seminal texto sobre el paradigma indicial. Ginzburg asumía que la historia "nunca pudo» con el paradigma galileano triunfante desde el siglo XVIII, porque el conocimiento que genera no aplica para las condiciones de experimentación, replicabilidad y generalización. Según Ginzburg, «El conocimiento histórico, como el del médico, es indicial, indirecto y conjetural». Carlo Ginzburg, "Raíces de un paradigma de inferencias indiciales," en Mitos, emblemas, indicios. (Barcelona: Gedisa, 1989), 199. De ahí la conocida analogía de Ginzburg: «el historiador es un cazador», va tras las huellas de su presa. Ginzburg, Raíces..., 197. A tono con sensibilidades poscoloniales, es central la discusión epistolar que mantienen sobre este texto de Ginzburg el historiador Adolfo Gilly y el Subcomandante Marcos del Ejército Zapatista de Liberación Nacional mexicano a mediados de la década de 1990. Gilly le envía a Marcos una copia del texto de Ginzburg. El subcomandante le contesta, en una acalorada discusión, que el texto está muy bien, pero tiene un problema central: no piensa al cazador. Lo toma como un sujeto universal. Y el cazador (el historiador) está atravesado por posiciones de raza, género, clase, etnia, que condicionan la lectura de los indicios. Ver Adolfo Gilly, Subcomandante Marcos, Carlo Ginzburg, Discusión sobre la historia (Madrid: Taurus, 1995), 16-17. 
la repetición, la continuidad y el «retorno del acontecimiento» se postulan frecuentemente. Yo mismo abordé en otro texto el pedido del Movimiento Indígena Argentino para la inclusión del genocidio de finales del siglo XIX como una "violencia desaparecedora" de larga duración que debía suturarse con las desapariciones de las últimas dictaduras de la década de 1970. Bajo señalamiento de cometer el pecado del anacronismo y en pos de la defensa de la "especificidad», fue imposible que sus demandas se escucharan: los historiadores (porteños) marcaron el límite (y fue, aquí sí, un límite público y político) ${ }^{60}$. Pero el movimiento indígena no reclamaba la identidad de los dos hechos, no pretendían asumir que las campañas «al desierto» de la década de 1870 y la Doctrina de la Seguridad Nacional, que se impuso desde fines de la década de 1960, eran el mismo acontecimiento. Lo que requerían era desnudar una interdicción, mostrar un tabú: que la posibilidad de historiar la violencia necesita de una imaginación que salte por encima del tiempo homogéneo, que produzca conexiones impedidas, que impugne la secuencia para exhibir la estructura, la reedición de aquella acción soberana de dominio que erigió un relato histórico cuyo rol central fue prohibir ese develamiento ${ }^{61}$.

Michael Taussig ${ }^{62}$ estudió también de ese modo a los huitoto. Explicó que cuando los pueblos están sometidos a la conquista continua apelan a los muertos y a los espectros, a su retorno en los relatos. Pero no lo hacen reclamando una imaginación temporal pre-moderna y cíclica; una forma atávica, otra o incomprensible. En absoluto: los muertos que aparecen en la historia-montaje de la que parte Taussig; exigen

60 Materia de otro texto sería discutir la distinción entre especificidad, singularidad y excepcionalidad. Bajo el aspecto del tiempo lineal y del cambio constante, se corre el riesgo, como diría Peter Hulme, de que todo acontecimiento "mirado muy de cerca» sea excepcional. Y ese es un problema no solo epistémico sino político, Peter Hulme, «Postcolonial theory and the representation of culture in the Americas,» en Coloniality at large. Latin America and the Postcolonial Debate, eds. Mabel Moraña, E. Dussel y C. Jáuregui (Durham: Duke, University Press, 2008), 392; Para el concepto de anacronismo y su relación discursiva con la verdad histórica véase Jacques Rancière, «Le concept d'anachronisme et la verité de l'historien,» L'inactuel, $n^{\circ} 6$ (1996): 53-68. 61 Mario Rufer, La nación en escenas. Memoria pública y usos del pasado en contextos poscoloniales (México: El Colegio de México, 2010), 255-303.

62 Michael Taussig, Chamanismo, colonialismo y el hombre salvaje (Bogotá: Norma, 1997), 439-470. 
salir de la estampa cultural del reconocimiento. Exigen una imaginación temporal que considere la repetición, que pueda complejizar la idea de proceso con la reedición del pasado en tanto subyugación y dominio. En diferido, pero constante. Sobre este tópico y convocando a las formas culturales de los huitoto, Taussig propondrá:

Los "fragmentos inconexos" que subsisten en ellos no son testimonio de la tenacidad de la tradición, como podría sostener el historicista. Son en cambio imágenes míticas que reflejan y condenan la apropiación experiencial de la historia de la conquista, en cuanto tal historia parece formar analogías y correspondencias estructurales con las esperanzas y tribulaciones del presente" ${ }^{\text {*3. Para agregar }}$ luego que este tipo de apropiación del pasado es "anárquico y rebelde en su rechazo de la cronología y de la exactitud histórica" ${ }^{\prime 4}$.

De ahí que en su alusión a las tesis sobre la filosofía de la historia de Walter Benjamín, Taussig ${ }^{65}$ señale que la salida no es rescatar una "tradición del oprimido» que sedimente en un discurso histórico secuencial, coherente, secularizado o racional. Para los vencidos, la historia estará hecha siempre de las conexiones que habilitan los espectros, las imágenes conectivas, los montajes temporales, los encantamientos. La paradoja es clara: no hay archivo para la historia del Otro más que acechar al discurso soberano con aquello que él mismo impugnó (y a lo que, dicho sea de paso, ese discurso soberano le teme).

63 Taussig, Chamanismo, colonialismo y el hombre salvaje, 442.

64 Javier Sanjinés también apela a esta noción cuando contrapone el ensayo a la historia, com géneros. Rescata que solo se ha visto el ensayo en la epopeya fundadora (Sarmiento, Martí, etc.) y no a los que buscaron dotar de una imaginación narrativa que ponderara la memoria como ruina, como relato fragmentario que desafía la temporalidad racional, secular y vacía de la Historia. "Opuesta a [la] perspectiva historicista, el ensayo tal y como lo pienso debe necesariamente reinsertar la discontinuidad del pasado invisible en la larga duración de la historia. Como experiencia turbulenta del mundo empírico, el ensayo está hoy mejor preparado para lidiar con los problemas de comunidades activas, de comunidades "en movimiento", que el gesto pretencioso de las épicas nacionales, las cuales, al olvidar las experiencias asincrónicas del otro, tienden a homogeneizar y alinear todo». Javier Sanjinés, Embers of the Past: Essays in Times of Decolonization (Durham: Duke University Press, 2013), 21, DOI: https://doi.org/10.1215/9780822378815.

65 Taussig, Chamanismo, colonialismo y el hombre salvaje, 457-459. 
En el año 2017 en la provincia patagónica argentina de Río Negro pasó algo peculiar que retrata ese temor, y que refuerza la brecha historia/cultura como signo de soberanía. A fines de ese año la legislatura del estado local reconocía «rituales calendáricos» del pueblo originario mapuche como parte del patrimonio cultural de la nación. Con pocas semanas de distancia, la Prefectura Naval -fuerza de seguridad policial con carácter federal- se trasladaba al Lago Mascardi de esa provincia y ocupaba y desalojaba con represión armada los territorios mapuche que contaban con protección jurídica transitoria, exactamente donde el mismo Estado había "reconocido" cultura y patrimonio unos días antes. El motivo: la supuesta existencia de una célula peligrosa llamada RAM (Resistencia Ancestral Mapuche) ${ }^{66}$. Lo interesante para nosotros es que en varios medios de comunicación la ministra de seguridad en turno, Patricia Bullrich, hizo hincapié en que una cosa eran los derechos culturales y otra cosa «los fundamentos de la República y el futuro nacional», que era necesario defender por «la cantidad de sangre derramada para forjar nuestra historia» ${ }^{67}$. Defender con la perdurable escisión entre historia soberana y diferencia cultural; defender con las armas. Al mismo tiempo, la vicepresidenta de la República en ese entonces, Gabriela Michetti, habló de la necesidad de interceptar esa "amenaza», dado que en los predios

66 Nunca se comprobó la existencia de la RAM y todo indica que fue un montaje del gobierno en turno para sembrar suspicacia sobre los reclamos indígenas por el territorio y sobre la militancia de organizaciones por la defensa del medioambiente ante el impacto del extractivismo minero. En el momento en que escribo este texto, quien fuera en 2017 la Ministra de Seguridad encargada del operativo, Paticia Bullrich, está imputada por presunto espionaje ilegal a líderes indígenas. «Imputada por espiar y reprimir a los mapuches», Página 12 [on line], acceso el 17 de mayo de 2020, https://www.pagina12.com.ar/228723-imputada-por-espiar-y-reprimir-a-losmapuches.

67 En su análisis sobre «lo que Freud hace con la historia», De Certeau lo resume en las palabras del epígrafe de este artículo: «cada discurso social borra los síntomas que le han permitido nacer». De Certeau, La escritura de la historia, 285. Si en el asilo los síntomas del neurótico desaparecen bajo la "razón médica», en la historia el síntoma de la otredad vencida desaparece bajo la lógica archivística de la «verdad documental» y aparece intermitentemente como otra cosa. Cuando la cultura "cree que se dedica a cuidar» su propia estabilidad por medio de la evidencia, en realidad lo que hace «es ocultar de otro modo y mejor» De Certeau, La escritura de la historia, 285. 
reclamados y ocupados por indígenas se habían secuestrado armas, material peligroso y «hasta lanzas» ${ }^{68}$.

Una doble posesión acompaña al indio bucólico de la inocua belleza: una doble que reafirma al indio conquistado. La escritura de la historia y la fijación de la cultura como un rostro de Jano: el único Otro permitido es el que ha sido pacificado por la guerra y domesticado por la historia. Cuando la cultura pacificada se desborda y muestra su contravención, su poder de negar, entonces es traída rápidamente al lenguaje soberano de la historia: como tal, es una amenaza al tiempo lineal del progreso, del estado y del capital que debe ser, las veces que sea necesario, vencida.

\section{A modo de cierre}

¿Por qué no se le/nos mueve «ni un pelo» con aquellos muertos? Porque han sido construidos como distancia pura. Para el discursoinstituido, asumir que «esos son también mis muertos», que una conexión los trae al presente en tanto identidad, en tanto mismidad, solo puede ser mito o anacronismo. En un texto reciente con Valeria Añon señalábamos:

la repetición sólo existe en tanto diferencia. En la medida en que el tiempo lineal y vacío de la modernidad coloca a la diferencia en el pasado histórico, impide percibir la repetición, la prohíbe, la transforma en el tabú interdicto a la imaginación histórica: sólo puede concebirla en términos de una anomalía, de una "falta de conciencia histórica" de aquellos que no pueden salir del pensamiento "cíclico" del tiempo y aluden, inevitablemente, a espectros que no tienen entidad empírica ${ }^{69}$.

Pero para quienes estamos de «este lado» de la diferencia colonial tendríamos que admitir que ni la historia es irrepetible, ni el otro se subsume en la organización del archivo.

68 «Michetti 'supone' que los mapuches atacan con lanzas», El Patagónico, 03 de diciembre de 2017, https://www.elpatagonico.com/michetti-supone-que-losmapuches-atacan-lanzas-n3051981.

69 Añón y Rufer, «Lo colonial como silencio, la conquista como tabú,» 126. 
Las disputas por mantener el dogma de la «no repetición», por apuntalar el tiempo lineal de la soberanía y al mismo tiempo delimitar el atributo pacificado de la cultura es una mancuerna de gubernamentalidad recurrente en contextos poscoloniales actuales, justamente porque no hay forma de mantener el dominio colonial de los otros en un estado de derecho sin artilugios disciplinares que lo habiliten, y al mismo tiempo oculten esa habilitación.

El caso de los huitoto y sus montajes, del Movimiento Indígena Argentino y su insistencia desoída en mostrar la desaparición como continuidad histórica, el burdo comentario ministerial de que «una cosa es la cultura y otra la república», o el absurdo atavismo de las «lanzas mapuche» en palabras de una mandataria, muestran que cuando la incisión amenaza, cuando la alteración devela el secreto, la brecha entre cultura e historia tiene que redefinirse y afirmarse iterativamente. Ante la variación que burla la estructura, el poder soberano interviene reajustando el conjuro.

Pero el cierre es imposible. Eso que está «fuera del texto» y que «se nota» en él, como se pregunta De Certeau en uno de los epígrafes de este artículo, no es un contra-texto, pero alcanza para mostrar la parroquialidad del discurso de la historia y su temerosa inestabilidad. Esa variación del discurso de lo mismo muestra la contingencia de su escritura, la mantiene abierta, impide su cancelación. En la Wanka Danza del Perú y en la Danza de la Pluma de México, ambos bailes sobre la guerra de Conquista, algunas veces el capitán europeo pierde la batalla. Quizás porque en una historia de los subalternos importa que el tiempo sea imaginado como abierto en tanto historia de lo posible, y no como acontecimiento en tanto relato de soberanía. Tal vez haya que pensar que la historia en clave subalterna no es "otra versión del pasado», sino la otra historia posible. 


\section{Bibliografía}

Adorno, Rolena. «Reconsidering colonial discourse for Sixteenth and Seventeenth-Century Spanish America.» Latin American Research Review, ${ }^{\circ} 3$ (1993): 135-145.

Akinjogbin, I. A. Dahomey and its neighbors (1708-1818). Cambridge: Cambridge University Press, 1967. . "Dahomey and its neighbors: a revisited history," West African History after Decolonization. Ifé: University of Ifé, 1982.

Álvarez, Paulina. «Tres niños para la memoria. Arqueología, exhibición y poder en los Niños del Llullaillaco, Salta, Argentina.» Tesis de Maestría en Comunicación y Política, Universidad Autónoma Metropolitana-Xochimilco, México, 2019, Inédita.

Anghie, Anthony. "Francisco de Vitoria and the colonial origins of International Law.» En Laws of the postcolonial, 89-108, editado por Eve Darian-Smith y Peter Fitzpatrick. Ann. Arbor: The University of Michigan Press, 1999.

. Imperialism, Sovereignty and the Making of International Law. Cambridge: Cambridge University Press, 2004. DOI: https://doi.org/10.1017/CBO9780511614262.

Añon, Valeria, y Mario Rufer. «Lo colonial como silencio, la conquista como tabú: reflexiones en tiempo presente.» Tabula Rasa, $\mathrm{n}^{\circ}$ 29 (2018): 107-131. DOI: https://doi.org/10.25058/20112742. n29.06.

Arguedas, José María. Todas las sangres. Lima: Editorial Horizonte, 2015, [1965].

Carbó, Margarita. «De la República de Indios a la corporación civil. Vivir bajo permanente amenaza.» Scripta Nova. Revista Electrónica de Geografía y Ciencias Sociales Vol. X, nº 218 (2008): 741-798.

Castellanos, Alicia. "Para hacer nación: discursos racistas en el México decimonónico.» En Los caminos del racismo en México, 
coordinado por José Jorge Gómez Izquierdo, 89-115. México: Plaza y Valdés Ed., 2005.

Castellanos, Rosario. Balún Canán. México: FCE, 2006 [1957].

Chakrabarty, Dipesh. Provincializing Europe: Postcolonial Thought and Historical Difference. Princeton: Princeton University Press, 2000.

Chatterjee, Partha. La nación en tiempo heterogéneo y otros estudios subalternos. Buenos Aires: Siglo XXI, 2004.

De Certeau, Michel. La escritura de la historia. México: Universidad Iberoamericana, 2006, [1975].

. La cultura en plural. Buenos Aires. Nueva Visión, 2009, [1980].

Código Federal de Procedimientos Penales. 2016, 17 de junio. Capítulo IV, Peritos.

Constitución Política de los Estados Unidos Mexicanos, artículo 2, 2001, 8 de agosto, Garantías Individuales.

Derrida, Jacques. Mal de archivo. Una impresión freudiana. Madrid: Trotta, 1997.

Didi-Huberman, George. Pueblos expuestos, pueblos figurantes. Buenos Aires: Manantial, 2014.

Diouf, Mamadou, comp. L’historiographie indienne en débat. Colonialisme, nationalisme et sociétés postcoloniales. Paris: Sephis/Karthala, 1999.

Fabián, Johannes. Time and the Other. How Anthropology Makes its Object. Nueva York: Columbia University Press, 1983.

Foucault, Michel. Defender la sociedad. México: FCE, 2002. [1969].

La arqueología del saber. México: Siglo XXI, 2010, 
Gilly, Adolfo; Subcomandante Marcos; Ginzburg, Carlo. Discusión sobre la historia. Madrid: Taurus, 1995.

Ginzburg, Carlo. «Indicios. Raíces de un paradigma de inferencias indiciales.» En Mitos, emblemas, indicios, 185-240. Barcelona: Gedisa, 1999.

Gómez Izquierdo, José. «Racismo y nacionalismo en el discurso de las élites mexicanas. Historia patria y antropología indigenista.» En Los caminos del racismo en México, coordinado por José Jorge Gómez Izquierdo, 117-143. México: Plaza y Valdés Ed., 2005.

Gorbach, Frida. «El historiador, el archivo y la producción de evidencia.» En (In)disciplinar la investigación. Archivo, trabajo de campo y escritura, editado por Frida Gorbach y Mario Rufer, 187-202. Mexico: Siglo XX, 2017.

Gruzinski, Serge. La colonización de lo imaginario. Sociedades indígenas y occidentalización en México, siglos XVI-XVIII. México: FCE, 1991.

Hartog, François. Régimes d'historicité. Présentisme et expériences du temps. París: Le Seuil, 2003.

Hill Boone, Elizabeth, y Walter Mignolo, eds. Writing Without Words: Alternative Literacies in Mesoamerica and the Andes. Durham: Duke University Press, 1994. DOI: https://doi. org/10.1215/9780822379263.

Hulme, Peter. Colonial Encounters: Europe and the Native Caribbean, 1492-1797. Londres: Routledge, 1986.

«Postcolonial theory and the representation of culture in the Americas.» En Coloniality at large. Latin America and the Postcolonial Debate, editado por Mabel Moraña, E. Dussel y C. Jáuregui, 388-395. Durham: Duke, University Press, 2008.

Klor de Alva, José. «Colonialism and Postcolonialism as (Latin) American Mirages.» Colonial Latin American Review, I, 1-2 (1992): 3-23. 
Koselleck, Reinhart. Futuro pasado. Para una semántica de los tiempos históricos. Barcelona: Paidós, 1993, [1979].

Mignolo, Walter. "Colonial and postcolonial discourse: cultural critique or academic colonialism?.» Latin American Research Review 28, n 3 (1993): 120-134.

. «Semiosis colonial: la dialéctica entre representaciones fracturadas y hermenéuticas pluritópicas.» En De la hermenéutica y la semiosis colonial al pensar descolonial, 131148. Quito: Ediciones Abya Yala, 2013 [1989].

. El lado más oscuro del Renacimiento. Alfabetización, territorialidad y colonización, traducido por Cristóbal Gnecco. Popayán: Universidad del Cauca, 2016, [1995].

Pratt, Mary Louise. «In the Neocolony: Destiny, Destination and the Traffic in M eaning.» En Coloniality at large. Latin America and the Postcolonial Debate, editado por Mabel Moraña, E. Dussel y C. Jáuregui. 459-477. Durham: Duke University Press, 2008.

Quijano, Aníbal. «Colonialidad del poder, eurocentrismo y América Latina.» En Colonialidad del saber. Eurocentrismo y ciencias sociales. Perspectivas Latinoamericanas, compilado por Edgardo Lander, 201-246. Buenos Aires: CLACSO, 2000.

Rancière, Jacques. «Le concept d'anachronisme et la verité de l'historien.» L’inactuel, no 6 (1996): 53-68.

Rappaport, Joanne. The Politics of memory. Native historical interpretations in the Caribbean Andes. Londres: Cambridge University Press, 1990.

Riles, Annelise. «Aspiration and control: International legal rhetoric and the essentialization of culture." Harvard Law Review, 106, 3 (1993): 723-740.

Rufer, Mario. Reinscripciones del pasado. Nación, destino y poscolonialismo en la historiografía de África Occidental. México: El Colegio de México, 2006. 
«La temporalidad como política. Nación, formas de pasado y perspectivas poscoloniales.» Memoria y Sociedad, 14, 28 (2010a): 11-31.

La nación en escenas. Memoria pública y usos del pasado en contextos poscoloniales. México: El Colegio de México, 2010b.

. «La tradición como reliquia. Nación e identidad desde los estudios culturales.» En Nación y estudios culturales. Debates desde la poscolonialidad, editado por Carmen de la Peza y Mario Rufer, 37-59. México: UAM-Itaca, 2016.

. «El archivo. De la metáfora extractiva a la ruptura poscolonial.» En (In)Disciplinar la investigación. Archivo, trabajo de campo y escritura (160-186), editado por Frida Gorbach y Mario Rufer, 160-186. México: Siglo XXI - UAM, 2016.

. «La raza como efecto estructural de conquista. Una hipótesis de trabajo.» En Lo complejo y lo transparente. Investigación transdisciplinaria en ciencias sociales (101-128), editado por Eva Alcántara, Yissel Arce y Rodrigo Parrini. México: UAM-Imagia, 2018.

Sanjinés, Javier. Embers of the Past: Essays in Times of Decolonization. Durham: Duke University Press, 2013. DOI: https://doi.org/10.1215/9780822378815.

Segato, Rita. La nación y sus otros. Buenos Aires: Prometeo, 2007a.

«El color de la cárcel en América Latina. Apuntes sobre la colonialidad de la justicia en un continente en desconstrucción002E.» Nueva Sociedad, 208 (marzo-abril, 2007b): 142-161.

La colonialidad en ocho ensayos y una antropología por demanda. Buenos Aires: Prometeo, 2015.

Spivak, Gayatri. Crítica de la razón poscolonial. Madrid: Akal, 2009, [1997]. 
Taussig, Michael. Chamanismo, colonialismo y el hombre salvaje. Bogotá: Norma, 1997.

. La magia del Estado. México: Siglo XXI, 2015, [1997].

Thurner, Mark, y Andrés Guerrero, eds. After Spanish rule. Postcolonial predicaments of the Americas. Durham: Duke University Press, 2003. DOI: https://doi. org/10.1215/9780822385332.

Vitoria, Francisco de. Relecciones sobre los indios y el derecho de guerra. Madrid: Espasa Calpe, 1975, [1534].

\section{Periódico}

«Imputada por espiar y reprimir a los mapuches». Página 12 [on line]. Acceso el 17 de mayo de 2020. https://www.pagina12.com. ar/228723-imputada-por-espiar-y-reprimir-a-los-mapuches.

«Michetti 'supone' que los mapuches atacan con lanzas». El Patagónico, Buenos Aires, 03 de diciembre de 2017. https:// www.elpatagonico.com/michetti-supone-que-los-mapuchesatacan-lanzas-n3051981.

\section{Citar este artículo}

Rufer, Mario. "El perpetuo conjuro: tiempo, colonialidad y repetición en la escritura de la historia." Historia $Y$ MEMORIA, $\mathrm{n}^{\circ}$ Especial (2020): 271-306. DOI: https:/doi. org/10.19053/20275137.nespecial.11590. 